\title{
Complex View to Racing Car Upright Design and Manufacturing
}

\author{
Jakub Mesicek, Michal Richtar, Jana Petru, Marek Pagac, Kristyna Kutiova \\ Faculty of Mechanical Engineering, VSB - Technical University of Ostrava, 17. listopadu 15/2172, Ostrava, Czech Re- \\ public. E-mail: jakub.mesicek@vsb.cz, michal.richtar@vsb.cz, jana.petru@vsb.cz, marek.pagac@vsb.cz, kristyna.ku- \\ tiova@vsb.cz
}

\begin{abstract}
This paper describes selected aspects of design, optimization and manufacturing process of racing car's upright. Uprights described in this paper are formula student car's uprights. Formula Student is an international competition between university students, which must design and build a new prototype of the car each year, according to the FSAE rules. Uprights for most racing cars, formula student cars included, must meet wide specter of different requirements, like minimal weight, minimal stiffness etc. The first part of this contribution is concerned to design requirements and boundary conditions definition problematics like different uprights types. The following parts describe the material selection and possible optimization for the design and manufacture of the new uprights for the formula car. Manufacturing and final assembly of the part will be described.
\end{abstract}

Keywords: Upright, FEM, Manufacturing Technology, Racing Car, Aluminum Alloy

\section{Introduction}

For car components designed of Formula Student specific competition, it is necessary to have knowledge of several areas of topics that affect the upright requirements, especially precise component design, component manufacturing, and final assembly.

Formula Student racing car life cycle is very short, and designers are always under pressure because of time and cost conditions, design quality, material requirements and precise manufacturing. Upright design is limited by the quantity of defined vehicle body parameters, dynamical and kinematical requirements and finally by wheel suspension geometry.

The upright is a part of the vehicle chassis, which connects the suspension arms with the wheels. It is also a part of the steering and braking system - it transfers braking, driving and steering forces and moments from the wheel to the suspension arms. The upright is a rigid part of the vehicle and therefore must be as light as possible due to driving characteristics. Another essential feature of the upright is the stiffness, which is required because of accurate steering guidance. $[1,3]$

Low component weight and maximal stiffness are important requirements, which are crucial for racing cars and are very often difficult to accomplish [2]. Under these conditions, it is necessary to proceed to the component design, component manufacturing and final assembly. You also need to choose the right production technology and material type. In this decision, it is necessary to consider the technological possibilities, the experience of the designer and the manufacturer and finally, the financial costs associated with the production. [8]

\section{The basic requirements for upright design}

Upright transfers braking, driving and steering forces and moments from the road and wheel to the suspension arms and vice versa. The bearing set in the middle of the upright is situated, and the upright is mounted in this bearing set. Radial and axial forces by designed bearings must be absorbed. Driving axle has driving shaft mounted on the upright, with respect to homokinetic joints for torque transmission. [9]

Bearings in the chassis can be single row or double row, mostly with angular contact to provide axial force transmission. A brake disc or a brake drum is attached to the upright. There is also a rim mounted on the hub, using three, four, five, six screws or nuts. For some cars, the rim is attached with one central nut. Centering wheels ensure the collar on the hub. [11]

Upright is the rigid mass of the racing vehicle, therefore must be as light as possible due to driving characteristics. For this reason, it must be solid and rigid for precise wheel alignment. Racing car uprights have different design options, which correspond to the vehicle's suspension configuration. For production cars, the uprights are produced by castings made of gray cast or steel. For racing cars, the key parameter of upright is weight, due to this reason the uprights are often made from expensive materials by CNC machining. The upright structure is most affected by the type of wheel suspension and the used production technology. Basic requirements for racing car uprights can be described:

- minimal weight

- maximal stiffness

- good machinability

The design of racing cars must meet the various requirements that are caused by extreme road performance, for example air supply to brake discs for better cooling or a suitable aerodynamic curtain in the wheel. Is also part of the steering and braking system - it transfers braking, driving and steering forces and moments from the wheel to the suspension arms.

The brake caliper is also located on the upright. This means that the upright is loaded by braking forces and braking moments. The upright must be also rigid to avoid significant changes in steering geometry under the extreme loads.

The design of the upright is not strictly prescribed by the Formula Student rules, due to this reason the designer has an open space for his own creativity. During the design process, it is most important to know the position of 
the attachment points to the suspension arms, the wheel axis position, and the wheel center and the wheel sprocket. [4]

\subsection{Uprights types}

- $\quad$ welded upright (see Fig. 1)

Welded upright is made of steel or aluminum fragments and is one of the cheapest production options. Welding technology seems to be an ideal production option, because of different one for each wheel. However, we need a high number of precision mounting devices for fastening which

not negligible negative financial effect. These upright often have higher stiffness. The known disadvantage is a higher part weight.

- $\quad$ cast upright (see Fig. 1)

The most common casting material for racing car is aluminum alloy. In the case of passenger cars, uprights are also cast from steel. This method is technology challenging and requires a lot of experience for model creation and for casting mold creation. Generally, casting technology is often used for large-scale production. However, the bearing surfaces must also be machined. (see Fig. 1)
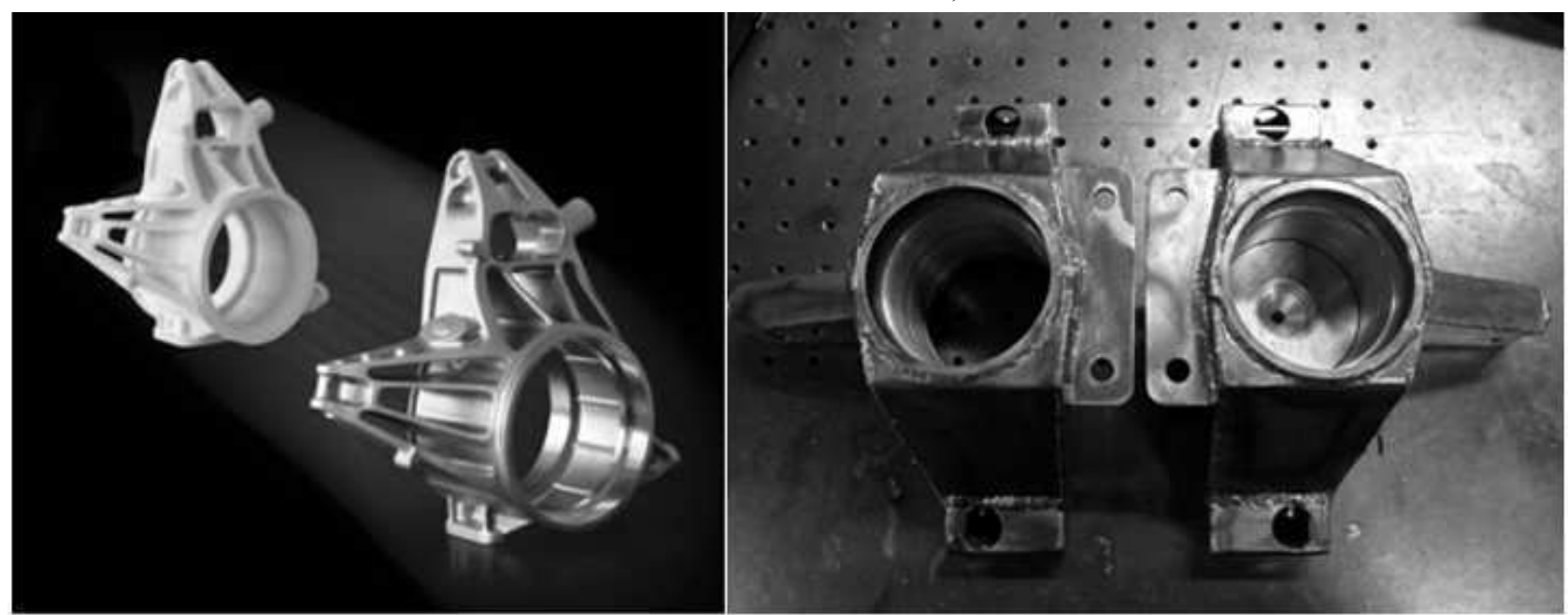

Fig. 1 Uprights - welded (left) and casted (right) [13]

- $\quad$ machined upright

Upright is a complicated part, therefore, five-axis machining centers are often used in production. The basic part is usually an aluminum alloy block. In non-serial production, the machining waste reaching up to $95 \%$ of the total weight of the product, and this is an economical complication [11]. This method of production is the most used in area of racing cars, because it is suitable for this type of part that is a very specific production. (see Fig. 2)

- composite upright

It is very complicated technology, with problems in design phase and in production phase. Both, the designer and the manufacturer, must have long-term experience in the field of designing and manufacturing of composite parts. Application of simulation software is very complicated, and the role of experimental testing is very important. The final product can reach up to ten times less weight than the conventional material, at the same stiffness. (see Fig. 2)

- $\quad 3 \mathrm{D}$ printed upright

It is also possible to use other advanced technology, such as metallic 3D printing. The product can be made of a variety of materials, such as stainless steel, aluminum alloy or titanium alloys. The printer produces almost any shape, there is only a limit to the total size of the part with respect to the space for printing in the machine. The designer can optimize the shape of the part and reduce its weight to a minimum. (see Fig. 2)
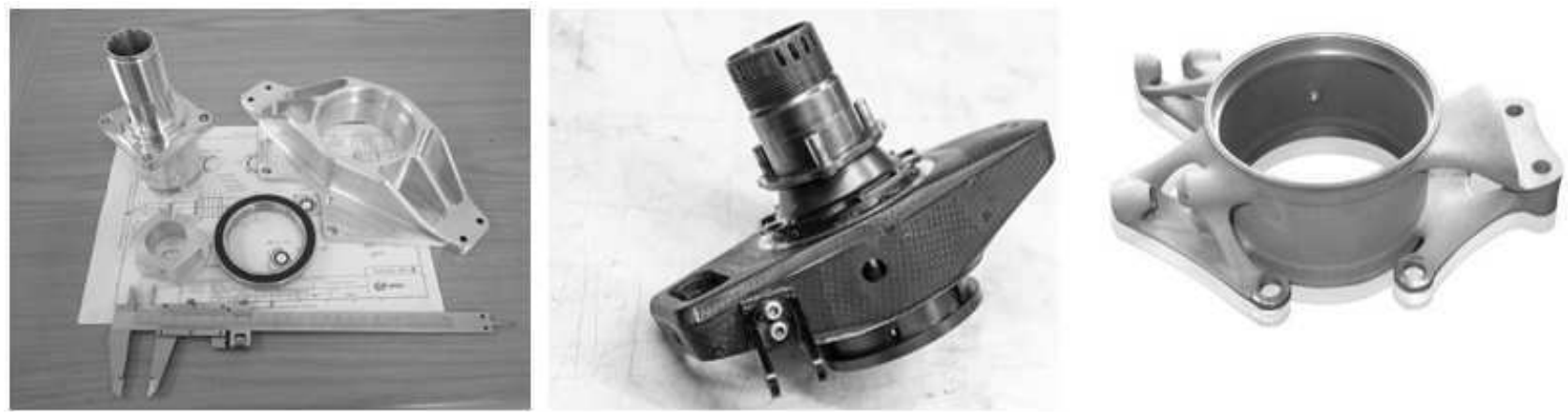

Fig. 2 Uprights - machined (left), composite (middle) and 3D printed (right) [14, 15, 16] 


\section{Upright design and materials}

Upright design in following steps has been realized. The first step, material selection, was one of the most important steps within design process. The machinability, strength and material density specially had been considered. The materials considered for the realization of the upright are shown in the table in Tab. 1.

Tab. 1 Considered materials and basic material properties

\begin{tabular}{|c|c|c|c|c|c|c|}
\hline \multirow{3}{*}{ Material } & \multirow{3}{*}{ Symbol } & \multirow{3}{*}{ State } & \multicolumn{4}{|c|}{ Minimal mechanical properties } \\
\hline & & & $\begin{array}{l}\text { Strength } \\
\text { limit }\end{array}$ & $\begin{array}{l}\text { Yield } \\
\text { strength }\end{array}$ & Ductility & $\begin{array}{c}\text { Hardness by } \\
\text { Brinell }\end{array}$ \\
\hline & & & $\mathrm{Rm}[\mathrm{MPa}]$ & $\mathrm{Rp} 0.2[\mathrm{MPa}]$ & A5[\%] & HBW 2.5/62.5 \\
\hline EN AW-1350A & EAl 99,5 & H112 & 65 & 20 & 23 & 18 \\
\hline EN AW-2014 & $\mathrm{AlCu} 4 \mathrm{SiMg}$ & T6 & 440 & 380 & 6 & 135 \\
\hline EN AW-2017A & $\mathrm{AlCu} 4 \mathrm{MgSi}$ & $\mathrm{T} 4$ & 380 & 230 & 10 & 107 \\
\hline EN AW-2024 & $\mathrm{AlCu} 4 \mathrm{Mgl}$ & $\mathrm{T} 4$ & 460 & 300 & 10 & 120 \\
\hline EN AW-2618A & $\mathrm{AlCu} 2 \mathrm{Mg} 1,5 \mathrm{Ni}$ & T6 & 380 & 300 & 6 & 105 \\
\hline EN AW-5083 & AlMg4,5Mn0,7 & H112 & 270 & 120 & 12 & 65 \\
\hline EN AW-5754 & AlMg3 & H112 & 180 & 80 & 15 & 50 \\
\hline EN AW-6401 & Al 99,9MgSi & T5/T6 & 235 & 185 & 14 & 70 \\
\hline EN AW-6060/6063 & AlMgSi/AlMg0,7Si & T5/T6 & 245 & 195 & 10 & 75 \\
\hline EN AW-6005A & AlSiMg & T5/T6 & 280 & 235 & 8 & 80 \\
\hline EN AW-6061 & AlMglSiCu & T5/T6 & 290 & 250 & 9 & 85 \\
\hline EN AW-6082 & AlSilMgMn & T5/T6 & 310 & 260 & 6 & 90 \\
\hline EN AW-6082 & AlSilMgMn & T5/T6 & 340 & 300 & 10 & 100 \\
\hline EN AW-6082 & AlSilMgMn & T5/T6 & 340 & 300 & 10 & 100 \\
\hline EN AW-6110A & AlMg0,9Si0,9MnCu & T5/T6 & 400 & 380 & 10 & 115 \\
\hline AA 6110 & $\mathrm{AlSi} 1 \mathrm{MgCu}$ & T5/T6 & 400 & 380 & 8 & 100 \\
\hline AA 6066 & AlSi1,5Mg1Mn1Cu & T5/T6 & 440 & 400 & 8 & 115 \\
\hline EN AW-7020 & $\mathrm{AlZn} 4,5 \mathrm{Mgl}$ & T5/T6 & 350 & 280 & 10 & 100 \\
\hline AA 7018 & $\mathrm{AlZn} 5 \mathrm{Mg} 1,5$ & T5/T6 & 410 & 360 & 10 & 115 \\
\hline EN AW-7022 & $\mathrm{AlZn} 5 \mathrm{Mg} 3 \mathrm{Cu}$ & T5/T6 & 480 & 410 & 6 & 140 \\
\hline EN AW-7075 & $\mathrm{AlZn} 5,5 \mathrm{MgCu}$ & T6/T73 & $530 / 455$ & $470 / 385$ & 8.VI & $145 / 130$ \\
\hline
\end{tabular}

The first considered material is EN AW 5083 AlMg4,5Mn, aluminum alloy with good workability. Mechanical properties are in the middle range, a tensile strength about $270 \mathrm{MPa}$. Material is suitable for welding. Technological features are excellent. It is well weldable, polished, anodized, has good corrosion resistance and is ductile. Turning is difficult, alloy is suitable for milling using a sufficient amount of emulsion. In contrast, milling of this alloy is seamless, the tool gluing occurs when the material is removed excessively. For the glossy surface, it is important to have a sharp tool, a rigid machine, high speed and a small material picking. [12]

The following material is EN AW 6060 - AlMgSi, it is the aluminum alloy that you can most often encounter.
Mechanical properties are slightly worse than alloy 5083, low strength. hardness and poor workability. Technological features are excellent. It is well weldable, polished, anodized, has good corrosion resistance and is ductile. Turning is difficult, alloy is suitable for milling using a sufficient amount of emulsion. When drilling the tool in front, it is recommended the hole to be drilled to the appropriate depth. [12]

Another material is EN AW 7022 - $\mathrm{AlZn} 5 \mathrm{Mg} 3 \mathrm{Cu}$ this material is characterized by uniform physical and mechanical properties across the cross-section thanks to their precise production technology. It is suitable for wide-area engineering, for cutting-edge cutting tools, construction of single-purpose machines, etc. This material is difficult 
to weld, has good anodicity and excellent workability. It is suitable for erosive machining, has excellent milling ability and strength up to $550 \mathrm{MPa}$. Cutting resistance is close to automatic steel. It is used in engineering, in the production of high-stressed machinery, defense and aviation. [12]

And next material is EN AW 7075 - $\mathrm{AlZn} 5 \mathrm{MgCu}$, material characteristics are similar to EN AW 7022 and is characterized by uniform physical and mechanical properties across the cross-section thanks to their precise production technology. It is suitable for wide-area engineering, for cutting-edge cutting tools, construction of singlepurpose machines, etc. This material is difficult to weld, and have very low workability, especially turning. It is suitable for erosive machining, has excellent surface quality and milling ability, and strength up to $500 \mathrm{MPa}$ and hardness up to $160 \mathrm{HB}$. Cutting resistance is close to automatic steel. It is used in engineering, in the production of high-stressed machinery, defense and aviation. [12]

Material CERTAL AlZn5Mg3Cu - EN AW 7022 for the design of the racing car upright has been selected.

First, unoptimized upright design is described in the Fig. 2 (left).

\section{Loading forces and final material specifica- tions for strength analysis}

Because of the specific vehicle data, some vehicle data by racing team have not been released for public access, the loading forces calculation will be only shortly described. Basic racing car data in the following table Tab. 2 are described and also with dimensions in Fig. 3 can be compared.

Tab. 2 Loading longitudinal $F x$, vertical $F z$ and lateral forces $F y$

\begin{tabular}{|l|c|c|c|}
\hline Racing car weight & $\mathrm{m}$ & 300 & $\mathrm{~kg}$ \\
\hline Wheelbase & $\mathrm{L}$ & 1600 & $\mathrm{~mm}$ \\
\hline Coefficient of adhesion & $\mu \mathrm{x}$ & 2 & - \\
\hline Center of gravity position & $\mathrm{ht}$ & 280 & $\mathrm{~mm}$ \\
\hline Wheel radius & $\mathrm{rd}$ & 235 & $\mathrm{~mm}$ \\
\hline Maximal torque & $\mathrm{Mh}$ & 750 & $\mathrm{Nm}$ \\
\hline
\end{tabular}

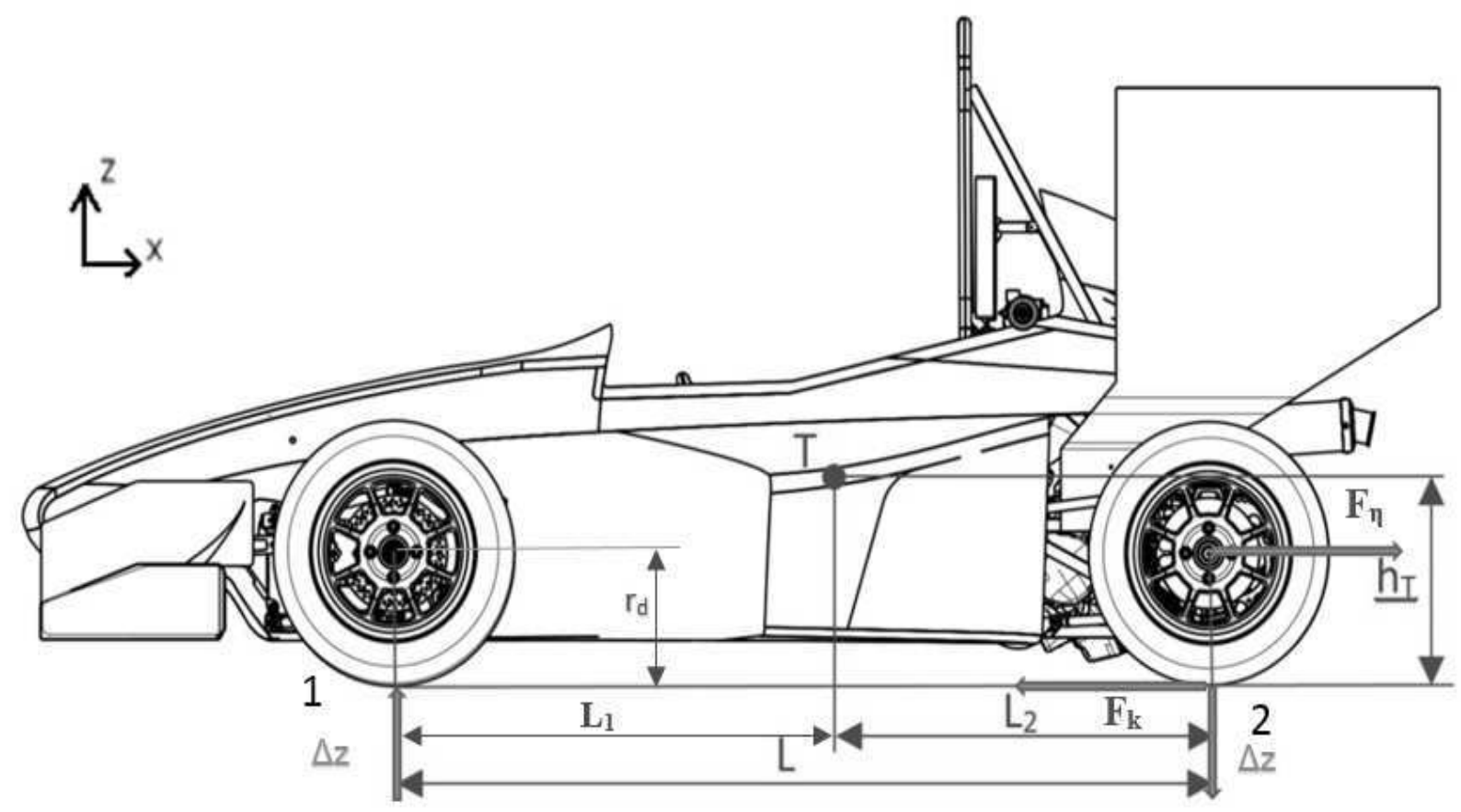

Fig. 3 Vehicle dimensions for vertical loading forces calculations

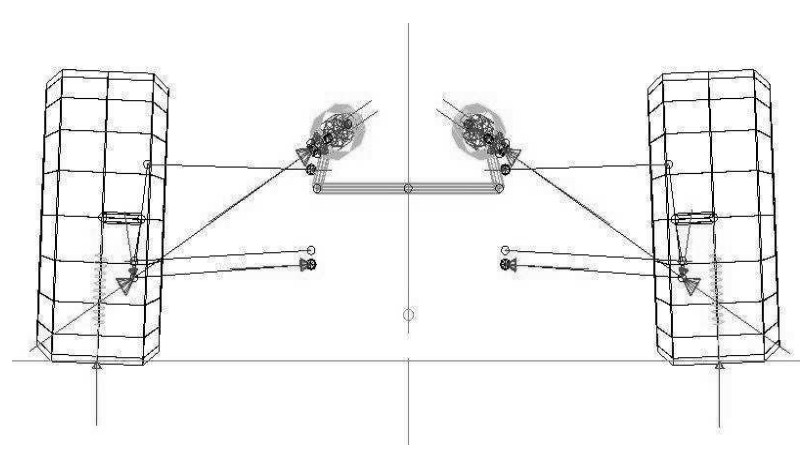

Fig. 4 Loading forces in suspension
Because of the specific vehicle data, some vehicle data by racing team have not been released for public access, the loading forces calculation will be only shortly described. Acceleration, braking, turning and dynamic impulse in calculations have been respected. Longitudinal forces Fx, vertical forces Fz and lateral forces Fy in described driving maneuvers have been calculated. Calculated forces Fx, Fy and Fz for reaction forces in connecting points investigation have been used (see Fig. 4).

Vehicle dynamics racing car odel has been used for loading forces calculation. Vehicle dynamics model is not a subject of this paper aim and is specific issue of car de- 
sign. Resulting loading forces, as an input for FEM analysis of upright are described in Tab. 3. Calculated loading force values are used as an input into the LOTUS suspen- sion analysis software environment. This analytical software calculates the reactions at each point of suspension. These reaction forces are inputs for strength and deformation analysis.

Tab. 3 Loading longitudinal Fx, vertical $F z$ and lateral forces $F y$

\begin{tabular}{|c|c|c|c|c|c|c|}
\hline \multirow{2}{*}{ Simulated situation } & \multicolumn{3}{|c|}{ Left wheel (outer) } & \multicolumn{3}{c|}{ Right wheel (inner) } \\
\cline { 2 - 7 } & $\mathrm{Fx}$ & $\mathrm{Fy}$ & $\mathrm{Fz}$ & $\mathrm{Fx}$ & $\mathrm{Fy}$ & $\mathrm{Fz}$ \\
\hline Breaking & $1620 \mathrm{~N}$ & - & $810 \mathrm{~N}$ & $1620 \mathrm{~N}$ & - & $810 \mathrm{~N}$ \\
\hline Turning & - & $3156 \mathrm{~N}$ & $1578 \mathrm{~N}$ & - & $82 \mathrm{~N}$ & $41 \mathrm{~N}$ \\
\hline Dynamic impulse & - & - & 1619 & - & - & - \\
\hline Acceleration & $1596 \mathrm{~N}$ & - & $810 \mathrm{~N}$ & $1596 \mathrm{~N}$ & - & $810 \mathrm{~N}$ \\
\hline
\end{tabular}

During the design, machining and manufacturing of upright the functional safety principles according standard ISO 26262 have been respected [7].

\section{Model optimization with respect to maximal stress and deformation}

See in the Fig. 5, first model has been optimized with respect to upright weight reduction. After the optimiza- tion the FEM analysis of the upright until the precalculated load forces has been applied. The conclusion of the FEM simulation is, that the stress is too high (see Fig. 5left). It achieves material yield strength values $410 \mathrm{MPa}$. The displacement about 0,194 $\mathrm{mm}$ also reaches high values, which could affect the car's driving performance, stability and safety.

Because of the high values of stress and displacement, the upright has been optimized to improve stiffness.
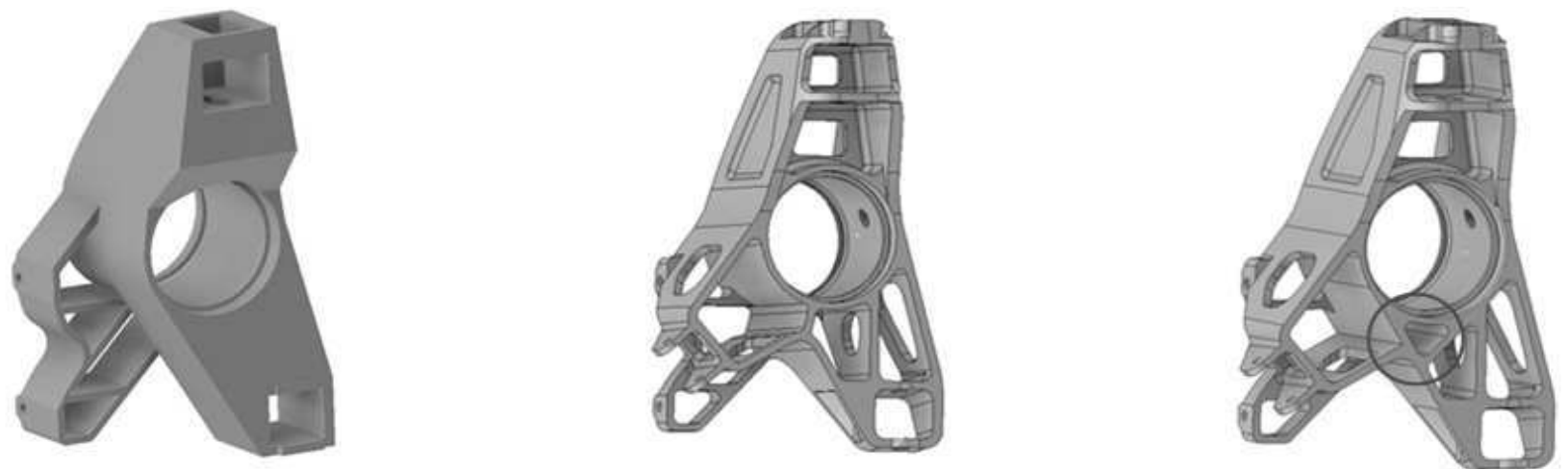

Fig. 5 Comparison of shape and weights for first graphic (left), after weight optimization (middle) and after optimization of weight and shape (right) at the point of maximum tension $(2.100 \mathrm{~kg}$ left, $1.114 \mathrm{~kg} \mathrm{middle,} 1,175 \mathrm{~kg}$ right)

For improving the stiffness and tension reduction, the model has been optimized in the part of the interconnection of attachment of the lower arm and the trailing arm. The lower attachment is connected in a straight line to the

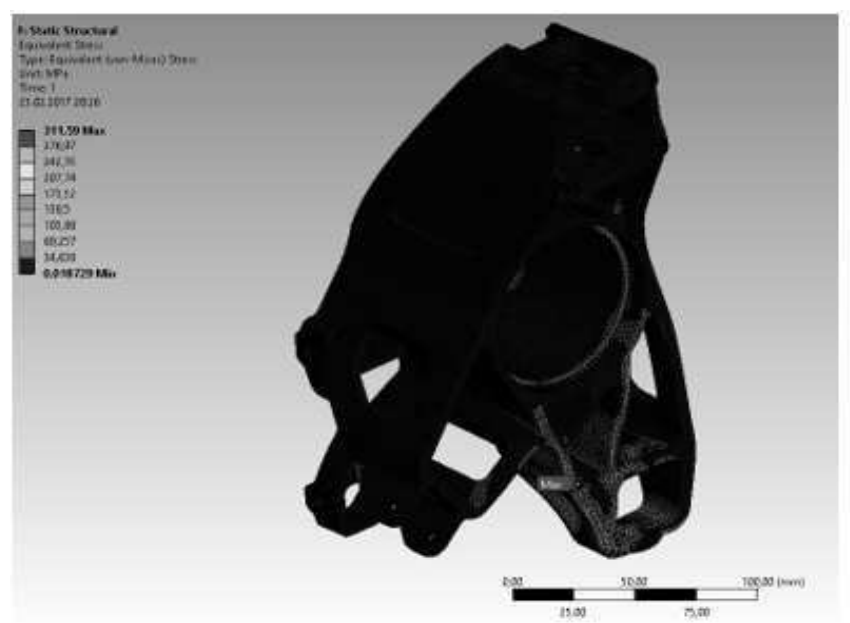

tangent of bearing alignment. One extra rib has been created to solidify the whole structure. However, the optimized upright has 61 grams more than the first upright design. Which in this cases was required, for safety and better performance. (see Fig. 5)

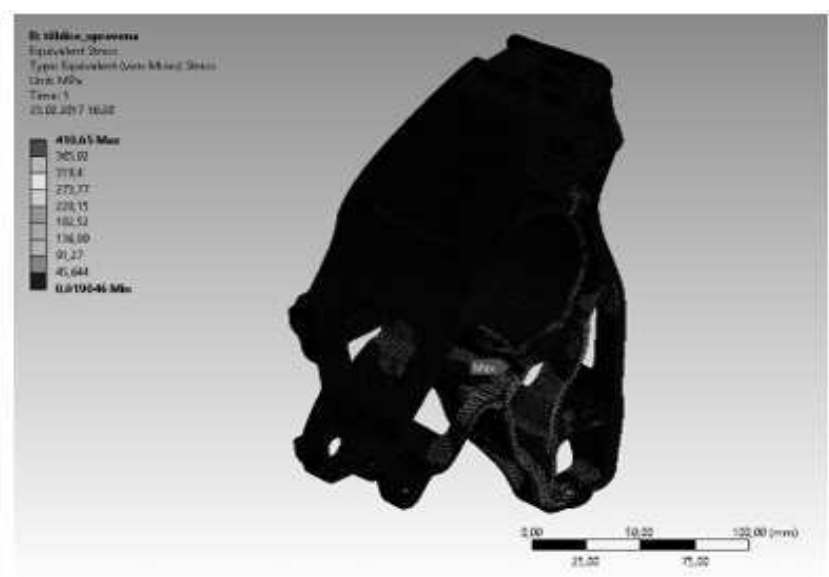

Fig. 6 Upright stress - after weight optimization (left) and after optimization of weight and shape (right) 
The result of the FEM analysis after the optimization looks good for manufacture, so the design fulfills the requirements established. The maximum reached stress was $311 \mathrm{MPa}$, which is below the yield stress with a safety factor of $k=1.3$. The deformation of the upright after optimization have been reduced by $0.1 \mathrm{~mm}$, using the same load. Now, the maximum deformation of $0.09 \mathrm{~mm}$ is between the tolerances allowable for this part of the car. This analysis guaranties, that the new part with the increased stiffness will have a solid performance on the race vehicle chassis. (see Fig. 6)

\section{Rear upright manufacturing and assembly}

Using the documentation, blueprints, calculations and the $3 \mathrm{D}$ models the technological procedure for the production of upright has been carried out (see Fig. 7). The

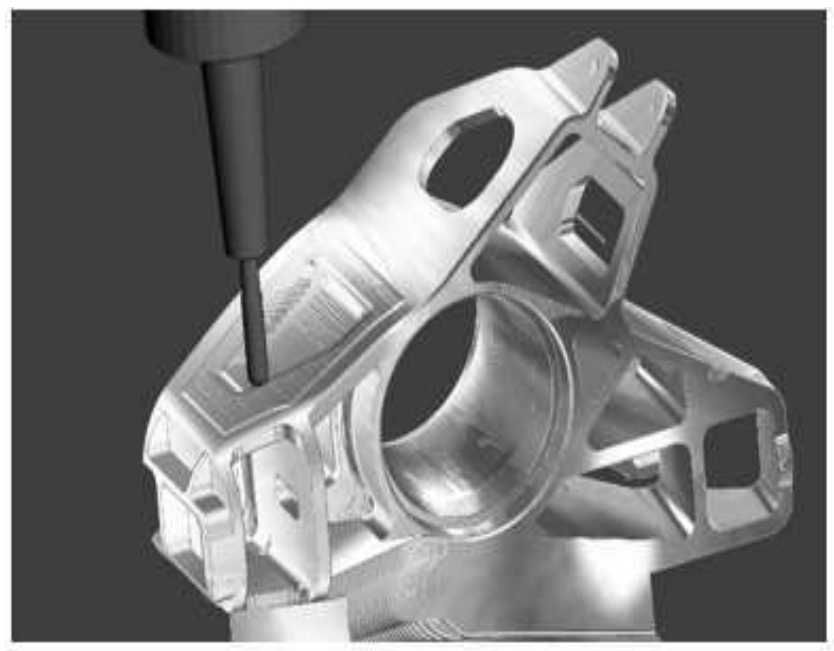

machining of upright using 5 axis $\mathrm{CNC}$ milling tool is shown in fig. 2. The upright is only using two clamps. The semi finished product for the component productions is the aluminum alloy block EN AW 7022 with dimensions $250 \times 200 \times 150 \mathrm{~mm}$ and $20 \mathrm{~kg}$ of weight. The final part weight is only 1.2 kilograms, so the production waste reaches $94 \%$. This is the tax for non-serial production of a special component.

During production, there was a problem with workpiece vibration, which caused uneven sections on the surface of the workpiece. Troubles through the machining process are interesting problematics as in several papers have been described [6]. Inequalities did not affect the functionality because they were not in place of the required exact dimensions.

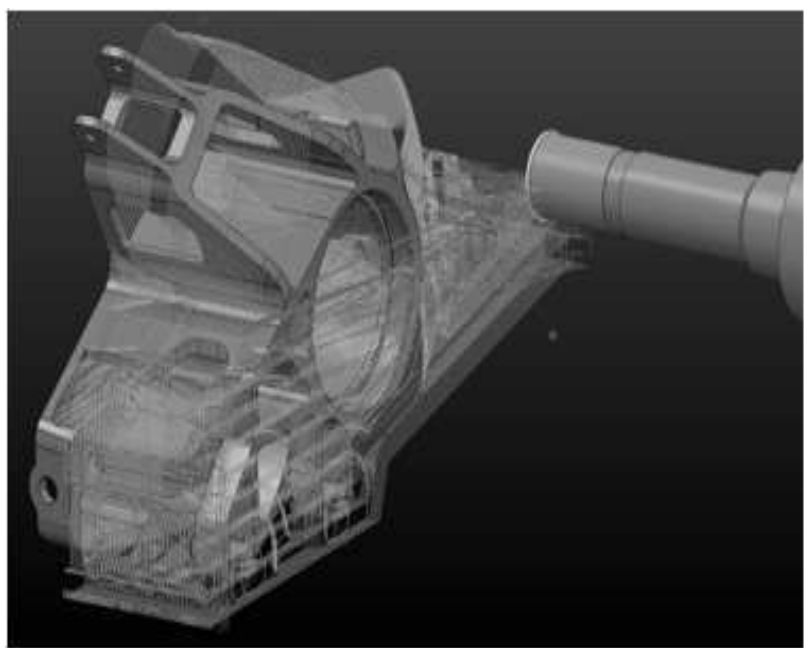

Fig. 7 Machining process simulation

During production, there was a problem with workpiece vibration, which caused some small scuffs on the surface of the workpiece. Inequalities did not affect the

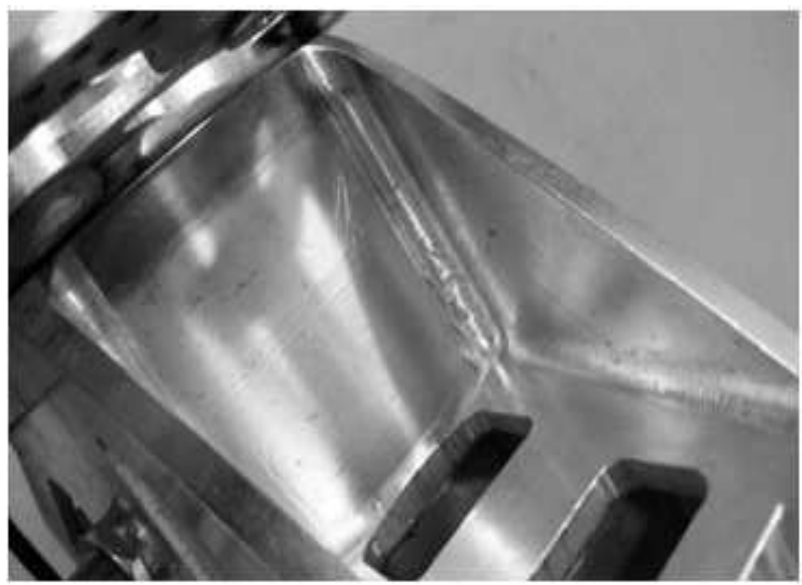

functionality because they were not in area of the required precise dimensions. (see Fig. 8)

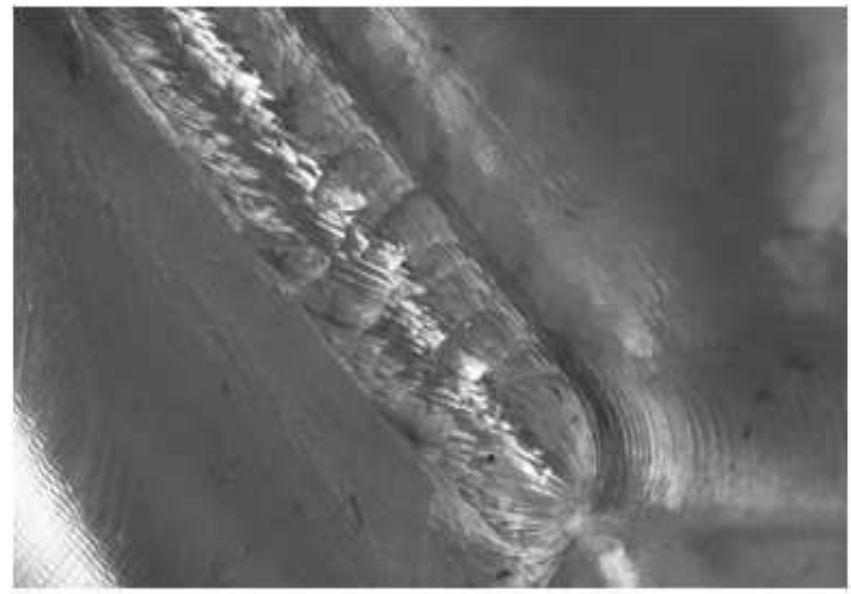

Fig. 8 The 5 axis CNC milling center - results of workpiece vibrations 

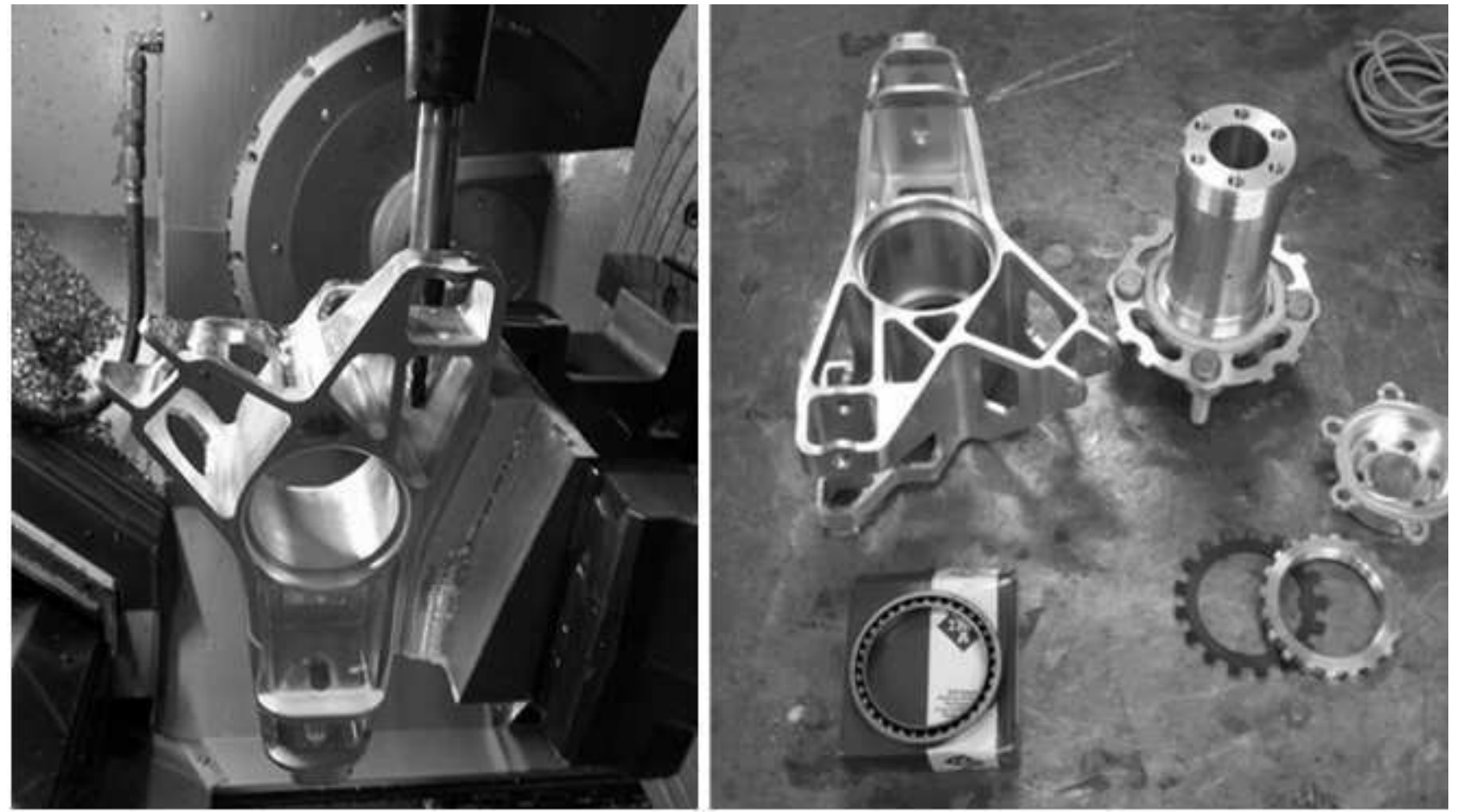

Fig. 9 The 5 axis CNC milling center - working on upright and its parts set

Finally, manufactured upright in road vehicles labs have been assembled and mounted to the racing car. For the final assembly standards tools have been used. Exploded upright set and racing car rear suspension fitted by designed and manufactured upright in Fig. 10 have been shown.
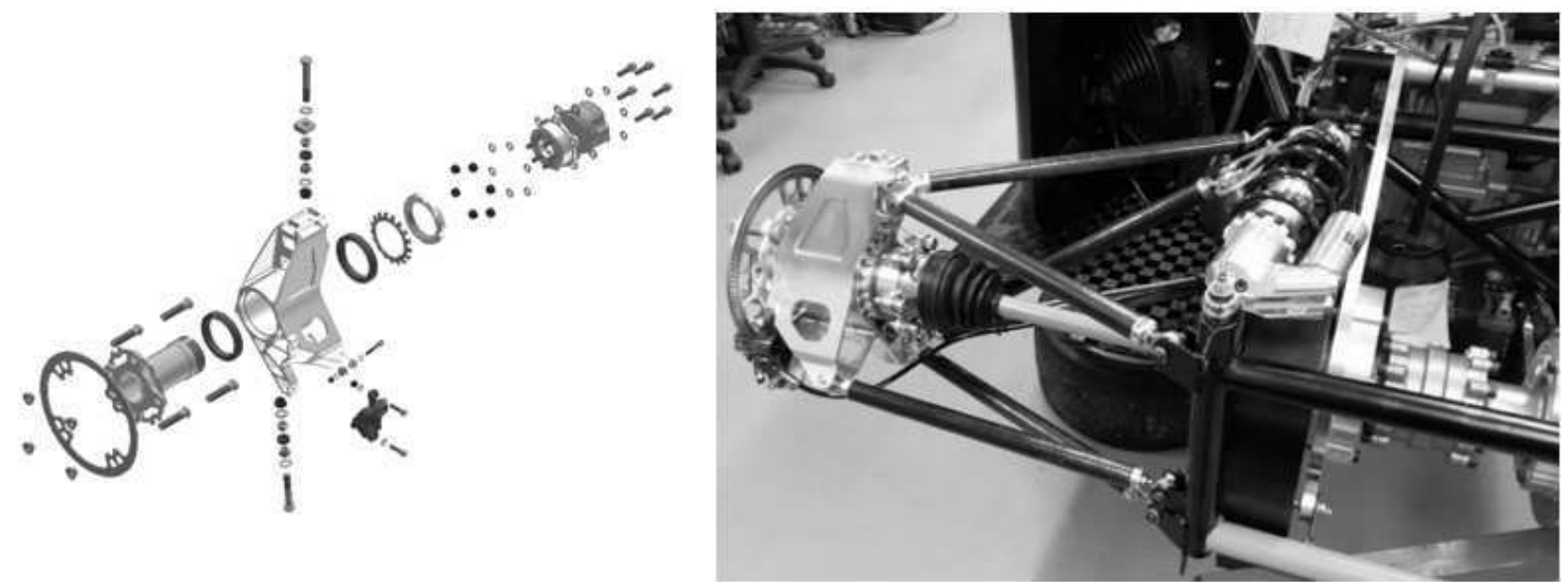

Fig. 10 Exploded upright set and racing car rear suspension fitted by designed and manufactured upright [5, 17]

\section{Conclusions}

Further body development should continue to be optimized. The use of shape generator software should be implanted to take advantage of this new feature in modeling software, that has been recently released. Shape generator is a new way to design efficient, lightweight parts, created with specified parameters. The model is created including the required mass, minimum thickness and symmetry. Optimization of the model using a shape generator creates a complex construction that can only be produced on $3 \mathrm{D}$ printers or multi axis $\mathrm{CNC}$ machining. The material should be non-corrosive steel with a strength over 550
$\mathrm{MPa}$, which has been already tested by our organization.

\section{Acknowledgment}

Article has been done in connection with projects Education system for personal resource of development and research in field of modern trend of surface engineering - surface integrity, reg. no. CZ.1.07/2.3.00/20.0037 financed by Structural Founds of Europe Union and from the means of state budget of the Czech Republic and by project Students Grant Competition SP2017/147, SP2017/149 and SP2017/126 financed by the Ministry 
of Education, Youth and Sports and Faculty of Mechanical Engineering VSB-Technical University of Ostrava.

\section{References}

[1] Formule SAE Rules, last review 2. 9. 2016. [online], [5.5.2017]. from: http://www.fsaeonline.com/content/2017-

18\%20FSAE\%20Rules\%209.2.16a.pdf

[2] VLK, F. (2006). Podvozky motorových vozidel: 3. aktualizované vydání. Brno: František VLK, 2006, Czech Republic

[3] SAJDL, J. (2017). Zavěšení kol. Autolexikon.net [online], [5.5.2017]. from : $<$ http://cs.autolexicon.net/articles/zaveseni-kol>

[4] LIŠČÁK, Š., MATĚJKA, R., RIEVAJ, V., ŠULGAN, M. (2006). Podvozky cestných vozidel. EDIS - Vydavatelstvo Žilinskej univerzity, Žilina, 2006. ISBN 80-8070-588-7, Slovakia

[5] Formula Student, VSB - TU Ostrava, Czech Republic [online], [5.5.2017]. from: http://formula.vsb.cz/portfolio/vizualizace-formule/

[6] ŠPALEK, F., SADÍLEK, ČEP, R., PETRŮ, J., KRATOCHVIL, J., ČEGAN, T. (2017). Difference between Cutting Surface of Al Foam and Solid Al Machined by WEDM Technology, In: Manufacturing Technology, Vol. 17, No. 5, Czech REPUBLIC, 2017, ISSN 1213-2489

[7] RICHTÁŘ, M., ŠMIRAUS, J. (2014). Functional safety utilization in road vehicles design. Proceedings: deterioration, dependability, diagnostics, University of Defence, Brno, Czech Republic, 2014, str. 171-178.

[8] FAMFULÍK, J., MÍKOVÁ, J., RICHTÁŘ, M., HALAMA, R. Random vector approach to the calculation of the number of railway vehicles to hold in reserve. Proceedings of the Institution of $\mathrm{Me}$ chanical Engineers, Part F: Journal of Rail and Rapid Transit, volume 230, issue 1, 2016, p. 253-
257.,1,253-

257 RIV/61989100:27230/16:86094744.

[9] HESTERINI, P. (2017). Přední náprava a ř́zení pro vůz CTU CarTech [online], [5.5.2017]. from: http://stc.fs.cvut.cz/history/2010/sbornik/papers/pdf/HesteriniPavel-338411.pdf , Czech republic

[10] ŠPALEK, F., PETRŮ, J., ZLÁMAL, T, MRKVICA, I., ČEP, R., KRATOCHVIL, J. (2016). Electro-Erosive Wire Cutting of Aluminium Foam, In: Manufacturing Technology, Vol. 16, No. 2, Czech REPUBLIC, 2016, ISSN 12132489

[11] VYMAZAL, R. (2008). Těhlice vozu kategorie SAE. VUT v Brně, Brno, 2008, Czech Republic

[12] Dural a jeho slitiny, Valsteel s.r.o. [online], [5.5.2017]. from: http://www.valsteel.eu/dural.htm

[13] Rensselaer Formula Hybrid Racing [online], [5.5.2017]. from: http://rpihybrid.blogspot.cz/2012/04/lots-of-progress.html

[14] DIBAE BUILD LOG. NMMU Racing [online]. 2013 [cit. 2017-05-06]. from: http://nmmuracing.nmmu.ac.za/The-project/DibaE-Build-Log

[15] Automotive: Formula Student Germany - EOS supports racing team by producing a topology-optimized steering stub axle. EOS EMANUFACTURING SOLUTION [online]. 2012 [cit. 2017-05-06]. from: https://www.eos.info/press/customer_case_studies/rennteam_uni_stuttgart

[16] Tankia 2016 upright [online]. 2016 [cit. 2017-0506]. from: http://www.imgrum.org/media/12884632065239696472202265709

[17] Hope Tech E4. Hope Tech [online]. 2014 [cit. 2017-05-10]. from: http://www.hopetech.com/product/tech-3-e4/ 